\title{
Introduction to the Special Issue Teacher Educators for Children with Behavioral Disorders (TECBD) Conference
}

\author{
Sarup R. Mathur (D) - Wendy Peia Oakes $(\mathbb{D} \cdot$ \\ Heather Griller Clark (D) Eric Alan \\ Common (D)
}

Published online: 29 July 2020

(C) Association for Behavior Analysis International 2020
S. R. Mathur $(\bowtie) \cdot$ W. P. Oakes · H. Griller Clark

Mary Lou Fulton Teachers College, Arizona State University, 1050 S. Forest Ave., \#402 Farmer Bldg., PO Box 871811, Tempe, AZ 85287-1811, USA

e-mail: Sarup.Mathur@asu.edu

E. A. Common

Department of Education, University of Michigan-Flint, Flint, MI, USA
The special issue starts with an article that makes a compelling case for early use of effective teacher practices in producing positive student outcomes. In this article, Scott and Gage examined the relation between teacher practices and student outcomes. They observed $\mathrm{K}-12$ classroom instruction for the use of three specific behavioral strategies - teaching focus, opportunities to respond, performance feedback - that promote active student engagement and decrease disruption. The authors randomly selected 1500 teachers in 59 schools to explore the associations between school mean rates of the effective instructional practices and school-level academic (math and reading scores) and behavioral (school suspension rates) outcomes. Results indicated that the use of opportunities to respond and positive performance feedback were significant predictors of positive school outcomes for students; fewer suspensions and a higher percentage of academic proficiency. The relationship was stronger for elementary schools. The authors suggested the importance of early use of effective instructional strategies to maximize the potential benefit of these strategies as part of prevention efforts. The authors recommend future research be attentive to implications of demographic and contextual variables, given the evidence that students of color, with disabilities, and living in poverty receive more negative teacher feedback (Scott et al. 2019) and inferior instruction (Losen and Martinez 2013).

Along with academic challenges, many children with EBD frequently lack the social skills needed to interact with others and require intervention to remediate this deficit. The next article presents a study on social skills 
conducted and authored by Hartzell and her colleagues. In this study, the authors used a multiple baseline across subjects design to examine the effectiveness of a social skills intervention package, previously shown to successfully increase social engagement in students with developmental disabilities (Hartzell et al. 2015), for three male elementary students with EBD. Individualized, explicit social skills instruction was paired with adult prompting and peer reinforcement. Target social skills were identified for each of the three students by using the Social Skills Improvement System Rating Scales (SSiS-RS; Gresham and Elliott 2008), observations, and interviews. Taking responsibility and conversational turn-taking were the identified skill needs for one student. Starting conversations and accepting direction/criticism from peers were the identified skill needs for the second student. Expressing feelings and self-advocacy were the identified skill needs for the third student. The dependent variable for all three students was social engagement in the lunchroom. Instruction was provided individually in each skill, followed by prompting and fading. Data were collected using partial-interval recording. Implementation fidelity and social validity data were also assessed. The fact that the intervention package in this study successfully increased social engagement for all students in the lunchroom, and generalized to the playground, suggest that the ability to prompt an individual skill for a student and have that skill reinforced by a peer may be critical to remediate deficits.

Noncompliance is a common characteristic of students with EBD and often results in reduced time for academic instruction. In the next article, Sabey et al. examined the effectiveness of precision requests as a standalone intervention for eight students with emotional disturbance served in a self-contained classroom for third through sixth grade students (all students were in 3 rd or 4 th grade). Precision requests refer to precise verbal directions delivered to improve or maintain student compliance. In this A-B-A-B withdrawal design study, Sabey et al. examined aggregate student-level data on the percentage of students' compliance and latency to comply, as well as examined the frequency and total requests delivered by the teacher. In this study, precision requests demonstrated a functional relation in increasing student compliance (log response ratio = $0.17)$ with no adverse effects on latency to comply. In addition to examining the effectiveness of the intervention, the participating teacher, paraprofessionals, and students rated the social validity of the intervention positively. The authors conclude with a discussion of limitations and recommendations for future research examining precision requests, including discussing ethical concerns of punishment-based procedures in school settings.

In the next article, Ennis and colleagues examined teachers' use of behavioral strategies to support young children's behavior in schools implementing a comprehensive, integrated three-tiered (Ci3T) model of prevention. The authors employed a multiple-baseline across participants single-case research design to examine the use of tiered coaching strategies for three early childhood teachers' use of behavior-specific praise, precorrection, and instructional choice. Results indicated a functional relation between Tier 2 coaching of emailed praise, examples, goal setting, and visual performance feedback and teacher use of strategies, for two teachers. Coaches provided a Tier 3 support, use of a vibratory cuing system, for the third teacher to meet implementation goal levels. Coaching was implemented with high levels of procedural fidelity. Teachers reported the coaching intervention to be socially valid; however, two teachers reported feeling overwhelmed by the coaching for meeting goals on three strategies at the same time. This study extends the literature on the use of a tiered approach for professional learning.

In the fifth article, Lane et al. examined pre-post changes in educators' perceived knowledge, confidence, and usefulness and actual knowledge of concepts in the Ci3T model of prevention. Fifty-three leadership team members participated in a yearlong practice-based professional learning series to design, implement, and evaluate a Ci3T model for their school. Results indicated statistically significant increases and large effect sizes in perceived and actual knowledge, perceived confidence, and perceived usefulness of concepts measured. The authors cautioned against making causal inferences of the meaningful impact as it was based on a descriptive study, and they suggested additional research using experimental designs. The implications of this study include (a) building and implementing a Ci3T model may immediately appeal to educators who need additional assistance in meeting students' behavioral and social needs; (b) professional learning experiences of participants can be enhanced by providing them ongoing coaching; and (c) creating a positive team dynamic where all team members have the opportunity to learn is essential. 
In the sixth article, Levine-Brown et al. showed that by establishing successful collaborations, educators can reduce job-related stress and improve student outcomes. Special educators working in self-contained settings can benefit from collaborative relationships. However, engagement in these effective collaborative relationships is influenced by teachers' social and emotional competencies (SEC). These authors explored how the structure of special educators' school-based social networks might be influenced by their SECs using a sequential, equal status (Quantitative + Qualitative) design. Five special educators from one private school system completed surveys that focused on their formal and informal collaborations, coteaching team quality, and their SECs. In-depth interviews were also conducted to expand upon the survey's findings. Results indicate that school network structures are unique and several SECs are critical for forming and maintaining school-based collaborations. Implications for fostering special educators' SECs and improving teacher collaborations relate to schools' cultures, rules, expectations, and value systems. It is possible that each school's educators may demonstrate unique associations among SECs and desired educational partners.

Addressing extreme school violence, and more specifically mass school shootings, is an important albeit elusive endeavor. In the last article, Collins et al. examined issues around mass school shootings, specifically those related to supporting students with EBD. The authors discuss the history and assumptions related to mass school shootings, as well as offer a brief commentary on prevention and intervention efforts. They provide context and justification for threat assessments as a more effective, research-based model of prevention in comparison to zero-tolerance procedures. The commentary concludes with implications to inform future research and raises calls for more work across researchers, policy-makers, and various other decision-makers to examine the effectiveness and potential effects of how, as a society, we analyze, prepare for, predict, prevent, and respond to mass school shootings.

This special issue highlights that students with behavioral challenges have complex needs and require multifaceted programming that interfaces between academic instruction and behavioral outcomes. Explicit linkages need to be established between student needs and programming. For example, one article highlights why teachers need to engage in the early use of evidence-based instructional practices to promote students' success in school. Another one shows that teachers can improve or maintain compliance with the precision request procedure. One more illustrates that social skills training can be beneficial for students with challenging behavior and can promote their overall functioning and relationships. In addition to addressing student needs, the special issue also emphasizes building teacher capacity by establishing tiered coaching strategies, collaborative networks, and professional learning opportunities. By creating positive team dynamics, teachers may feel more empowered and experience less stress and burnout, and they may be able to meet the academic and behavioral needs of their students more effectively. The last article calls for the need for professionals, policymakers, and scholars to come together to address and respond to mass school shootings, an issue that requires attention.

We are grateful to all the authors for their valuable contributions to the special issue. We sincerely appreciate the time and expertise of Claire St. Peter, Editor-in-Chief, who guided us through the transition and mediated the new editorial process for us. We thank our reviewers for their critical evaluation of the submitted manuscripts and constructive, helpful, and informed critiques that were useful in selecting these manuscripts. We appreciate the continued partnership between TECBD and the Council for Children with Behavioral Disorders (CCBD), and extend an invitation to our readers to join us at the 2020 TECBD conference (http://tecbd.asu.edu) that will be coordinated virtually. We still have a lot to do amidst COVID-19, as PK-12 education systems explore new ways for providing inclusive and equitable academic, emotional, behavioral, and mental health supports for children with disabilities and their families.

\section{References}

Gresham, F. M., \& Elliott, S. N. (2008). Social skills improvement system: Rating scales. Bloomington, MN: Pearson Assessments.

Hartzell, R., Liaupsin, C., Gann, C., \& Clem, S. (2015). Increasing social engagement in an inclusive environment. Education and Training in Autism and Developmental Disabilities, 50, 264-277.

Losen, D. J., \& Martinez, T. E. (2013, April). Out of school and off track: The overuse of suspensions in American middle and high schools. K-12 racial disparities in school discipline. The Center for Civil Rights Remedies. http://escholarship. org/uc/item/8pd0s08z

Scott, T. M., Gage, N., Hirn, R., \& Han, H. (2019). Teacher and student race as a predictor for negative feedback during instruction. School Psychology Quarterly, 34(1), 22-31. https://doi.org/10.1037/spq0000251. 